\title{
FORMATOS DA INTIMIDADE ${ }^{1}$
}

Reality shows emergem como agentes sobre noções de público e privado, cidadão e indivíduo, num contexto de declínio dos movimentos sociais

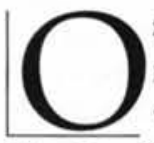

$\mathrm{s}$ chamados reality shows vêm marcando a cena cultural em diversos países nos últimos anos. Versões diferentes de gincanas dramáticas com participação de pessoas selecionadas dentre um contingente de milhares de candidatos circulam provocando polêmica por onde passam. Programas como Big Brother Brasil ou Casa dos Artistas - versões locais de matrizes estrangeiras - geram repercussão inédita na mídia. Durante os anos de 2000 e 2001, respeitáveis jornais diários, como Le Monde, na França, ou The Guardian, na Inglaterra, dedicaram páginas e páginas ao gênero televisivo.

Vale lembrar que a curiosidade do público sobre a intimidade das personagens em cena pode ser saciada nos episódios editados e televisados em horário nobre - $\mathrm{o}$ número e a duração dos episódios variam conforme a edição do programa - mas também em canais a cabo ou sites que exibem o copião do drama, ou seja, 24 horas de gravação diária, em tempo real. O caráter global do fenômeno estimula a especulação, freqüentemente na chave moral. Discute-se a natureza perversa ou inofensiva do fascínio exercido por programas que explorariam a humilhação de pessoas reais diante das câmeras. A crítica acusa o voyeurismo que esses experimentos estimulariam. Pouco se fala nas novidades do formato propriamente dito.

A trajetória de Big Brother, o programa inventado na Holanda pela Endemol, uma pequena produtora, que cresceu com o sucesso da invenção, é ilustrativa. A primeira versão do reality show estreou em setembro de 1999 naquele país. O formato foi logo exportado para a Inglaterra, Alemanha, Espanha e Estados Unidos. O número de países cresceu para os atuais 17 , que incluem países nórdicos mas também latinos. Além de Noruega, Dinamarca, Suécia e Bélgica, o programa existe também em países como o Brasil, Argen- 
tina, México, Austrália e África do Sul. Os limites de permissividade variam. Em Portugal, onde Big Brother já está na terceira edição, um casal transou ao vivo, desencadeando debate sobre a adequação de tal conduta na TV. A transgressão foi punida com a eliminação do jogo. Ao voltar à vida real, os dois participantes trataram de se redimir sacramentando rapidamente a união em casamento oficial.

Na Holanda, câmeras registram os detalhes mais escatológicos do cotidiano. Já a versão inglesa é mais pudica. Mas naquele país uma personagem gerou reações apaixonadas ao ameaçar um concorrente, no ar e ao vivo, com uma faca no pescoço: "E se eu te matasse agora?". Na Alemanha a produção quase não foi ao ar devido a ataques de líderes políticos e religiosos que acusaram o programa de violar a "dignidade humana", protegida pela Constituição. O Big Brother alemão só foi permitido com o compromisso de que as câmeras seriam desligadas diariamente durante uma hora. Mas o sucesso de público não necessariamente se deve à exibição de cenas consideradas aberrantes.

A primeira edição de Casa dos Artistas, por exemplo, parecia derivar seu apelo por, ao menos em parte, se dirigir à família reunida. Mas o frenesi que o programa inspira é parecido. Curiosamente, o resultado da exibição mais ou menos simultânea do mesmo gênero de programa em diversos países é que em cada um desses locais são discutidas mais ou menos as mesmas coisas. Há como que uma agenda comum vivida com especificidades ao redor do globo.

Após alguns anos de debate, há quem arrisque afirmar que a onda da TV realidade já passou. Talvez seja mais sagaz pensar que esses formatos meio novela sem roteiro, calcados no sensacionalismo, têm vida curta. Mas eles introduzem novas demandas.

O fenômeno vem associado a um conjunto de mudanças, que talvez possam ser entendidas como elementos de um novo paradigma do audiovisual, um paradigma que tem a ver com transformações que vêm compondo o que Manuel Castells denomina "sociedade em rede"2 . Há cerca de dez anos, a revista francesa Esprit ${ }^{3}$ publicou um dossiê premonitório intitulado Reality shows, uma nova era televisual?. A publicação acadêmica tematizou um fenômeno contemporâneo: a abundância de programas televisivos dedicados a divulgar histórias pessoais, íntimas e escabrosas, de pessoas anônimas que aceitavam revelar seus segredos diante das câmeras.

A França, nos anos 80 , quebrou o monopólio estatal da televisão. A introdução de canais privados, com sua lógica comercial, gerou uma mudança nos padrões de programação. Autores como Pierre Chambat e Alain Ehrenberg ${ }^{4}$ identificaram o crescimento dos reality shows. Eram programas confessionais e/ ou de auditório, parecidos com o programa de Jerry Springer nos Estados

\footnotetext{
2. CASTELLS, M. A sociedade em rede. São Paulo: Paz eTerra,2000. (N.Ed.)

3. CHAMBAT, Pierre. EHRENBERG. Alain. Reality shows, un nouvel âge télévisuel?(Reality show, uma nova era televisual?) Esprit. Paris, n. 1, jan./1993. Este número da revista Esprit traz além do artigo citado outros dois intitulados: EHRENBERG, A. La vie en direct ou le show de l'authenticifé (Direto da vida ou o show da autenticidade); CHAMBAT, P. La place du spectateur (de Rousseau aux reality shows) O lugar do telespectador-de Rousseau ao reality show). (N. Ed.) 4. A autora refere-se aos artigos acima citados. entre outras obras dos estudiosos franceses. (N.Ed.)
} 
Unidos ou com alguns quadros de programas como o de Sílvio Santos, Gugu Liberato ou Fausto Silva. Os autores chamaram a atenção para aspectos que permanecem atuais. Chambat e Ehrenberg procuram fugir das posições maniqueístas que identificam, no debate do início dos anos 90 naquele país - e que em larga medida permanece atual -, os que saudaram a nova programação como entretenimento inofensivo e os que reconheceram nela a prova cabal da decadência da moral e dos costumes.

Para além do esforço em definir o conteúdo ideológico dos programas, há aqui um esforço em entender o fenômeno nos seus próprios termos. Os reality shows emergem como agentes sobre noções de público e privado, cidadão e indivíduo, em um contexto de declínio dos movimentos sociais que marcaram a cena política francesa nas décadas de 60 e 70 .

\section{Os reality shows seriam}

indicadores da diluição das

fronteiras entre os gêneros da ficção e do documentário, como índices do aumento da participação do público na programação, como substitutos da programação política, expulsa do horário nobre pelos jogos televisivos.
Chambat e Ehrenberg apontam o que provavelmente se constitui no maior diferencial desses programas, que se mantém e cuja presença outros autores, como Roger Silverstone ${ }^{5}$, detectam em fenômenos de massa ligados à TV, como o funeral da princesa Diana. Com os reality shows, a TV deixa de ser meramente uma vitrina para voyeurs, telespectadores entendidos como receptores passivos do que vai na tela. Aqui a TV acena com a possibilidade de interação. E interação é intervenção. Como o casal de participantes do Big Brother português, eliminado da gincana graças ao preconceito contra o arroubo sexual em cena, que, ao sair da casa do espetáculo, se casou.

Aqui a experiência dos atores-personagens deles mesmos perpassa o palco e a platéia. Telespectadores e produtores da TV contemporânea buscam obsessivamente "a vida como ela é", para citar a vinheta do Aqui, Agora, programa que marcou época justamente por suas características de reality show. O indivíduo, suas ações e seus esforços para se realizar estão no centro do palco. A busca da autenticidade emerge nesses programas como um mote que faz com que a ficção apareça quase como traição.

\section{TV E INTERNET}

Possibilidades abertas pela internet migram para o meio de comunicação mais tradicional. O que começou como experimentos exibicionistas isolados em

5. Roger Silverstone é professor de Mídia e Comunicação, no Departamento de Sociologia, da London School of Economics and Political Science, autor, entre outros, de Televisión y vida cotidiana. Buenos Aires: Amorrortu, 1996. (N. Ed.) 
webcams $^{6}$ foi discutido em filmes como $O$ show de Truman, o show da vida ${ }^{7}$ e se realiza de maneira coletiva e compartilhada no reality show. Para além da intensidade e alcance elevados pela veiculação televisiva, os reality shows trazem em si a possibilidade da explicitação do caráter de construção do audiovisual. Longe do projeto ilusionista do cinema clássico de Hollywood, nos reality shows a existência não de uma, mas de cerca de 30 câmeras, é reconhecida pelos participantes dos jogos, universo que inclui o público. Na primeira versão de Casa dos Artistas, a edição dos episódios que iam ao ar se tornou, ela mesma, tema de disputa e discussão entre os participantes, que sentiam que seus personagens escapavam de sua interpretação, uma vez que, aos olhos do público, em larga medida, sua atuação era filtrada pelos cortes e seleção de trechos.

No mesmo programa, os interesses pessoais de cada um com a participação no programa também apareciam de maneira explícita. Supla repetia sem parar o comercial de seu CD, e assim por diante. Alguns declaravam que sua carreira precisava de um empurrão. A suspeita de manipulação dos telefonemas selecionados para votar foi levantada na mídia e enfrentada por Sílvio Santos, que rebateu as acusações dentro do programa. Mais do que escândalos e sensacionalismos, reality shows de ontem e de hoje, nos diversos países, compartilham um elemento que talvez tenha vindo para ficar.
Nem todas, mas as versões de maior sucesso do gênero envolvem, em alguma medida, a criação de redes de interação social.

É como se a imagem superficial do aparelho televisivo finalmente ensejasse uma profundidade não de campo, mas de acesso ao que pode estar acontecendo agora em um outro lugar. Alguém em casa telefona, fala com Sílvio Santos, comenta o que viu na casa, emite um voto que pode modificar o rumo do jogo. Seu voto pode ser influenciado pelo auditório, que se manifesta ativamente, pela notícia de jornal lida pelo apresentador, pelo discurso do participante isolado. No momento em que ele está ao telefone, a rede conecta vários desses pontos. Essa sensação de tocar o distante e desconhecido, torná-lo familiar, domesticá-lo e, principalmente, atuar sobre ele, faz o fascínio do reality show.

As versões mais atraentes descartam a figura do autor, fazendo com que os rumos da trama se delineiem como resultante da atuação não de uma vontade criativa, mas de diversas vontades, com graus diferentes de força e poder de manipulação. $\mathrm{O}$ paradoxo é que a ausência de autoria quase sempre resulta em tramas fracas, com pouco fôlego e de desgaste rápido. Falta o invencionismo do autor, mas não para repetir velhas fórmulas do melodrama, rígidas e em certa medida já desgastadas. O desafio para a dramaturgia contemporânea talvez se situe aqui, na fronteira avançada pelo reality show.

6. Webcams são câmeras de vídeo instaladas em ambientes externos, enviam imagens via satélite para qualquer ponto do planeta. É possível captá-las via internet, só exige que o internauta tenha banda larga. Em 2000 , foi instalada uma dessas câmaras na Praia do Pepino, Rio de Janeiro, as imagens são atualizadas a cada minuto. (N.Ed.)

7. O show de Truman, o show da vida. Direção: Peter Weir. EUA, 1998, 103min. (N.Ed.) 
Resumo: A autora discute a repercussão do reality show, nova modalidade de programação televisiva, que está presente em 17 paises Ocidentais. Os exemplares veiculados pela TV Globo - Big Brother Brasil - e pelo SBT - Casa dos Artistas - inspiram análises de todos os naipes. A autora salienta o exercício da interatividade do público com a programação e endossa a opinião de outros críticos que vêem este tipo de programação como manifestação da dicotomia entre público e privado. Ressalta, ainda, que este formato desafia a dramaturgia tradicional, introduzindo novos elementos ao paradigma do audiovisual.

Palavras-chave: reality show, audiovisual, televisão, Casa dos Artistas, Big Brother Brasil

\section{(Formats of intimacy)}

Abstract: The author discusses the repercussion of reality shows, a new mode of television programming present in 17 Western countries. The programs aired by Globo TV - Big Brother Brasil - and by SBT - Casa dos artistas (Artist's house) - inspired all kinds of analyses. The author emphasizes the use of audience interactivity with programming and endorses the opinions of other critics who see this type of programming as agents of notions about public and private, citizen and individual, in a social movement context (...) In the article, the author also stresses that this format challenges traditional dramaturgy, introducing new elements in the audiovisual paradigm.

Key words: reality show, audiovisual, Casa dos Artistas, Big Brother Brasil 